\title{
Accentuating the sources of mesenchymal stem cells as cellular therapy for osteoarthritis knees-a panoramic review
}

\author{
Sathish Muthu ${ }^{1,2} \wedge$, Madhan Jeyaraman ${ }^{2,3} \wedge$, Rashmi Jain ${ }^{3} \wedge$, Arun Gulati ${ }^{4} \wedge$, Naveen Jeyaraman ${ }^{2,5}$, \\ Gollahalli Shivashankar Prajwal $^{6} \wedge$, Prabhu Chandra Mishra ${ }^{2} \wedge$ \\ ${ }^{1}$ Assistant Orthopaedic Surgeon, Government Hospital, Velayuthampalayam, Karur, Tamil Nadu, India; ${ }^{2}$ International Association of Stemcell and \\ Regenerative Medicine (IASRM), New Delhi, India; ${ }^{3}$ Department of Orthopaedics, School of Medical Sciences and Research, Sharda University, \\ Greater Noida, Uttar Pradesh, India; ${ }^{4}$ Department of Orthopaedics, Kalpana Chawla Government Medical College \& Hospital, Karnal, Haryana, \\ India; ${ }^{5}$ Department of Orthopaedics, Kasturba Medical College, MAHE University, Manipal, Karnataka, India; ${ }^{6}$ Department of Orthopaedics, JJM \\ Medical College, Davangere, Karnataka, India \\ Contributions: (I) Conception and design: M Jeyaraman, S Muthu; (II) Administrative support: N Jeyaraman; (III) Provision of study materials or \\ patients: PC Mishra; (IV) Collection and assembly of data: R Jain, N Jeyaraman, GS Prajwal; (V) Data analysis and interpretation: S Muthu, M \\ Jeyaraman; (VI) Manuscript writing: All authors; (VII) Final approval of manuscript: All authors. \\ Correspondence to: Dr. Madhan Jeyaraman. Department of Orthopaedics, School of Medical Sciences and Research, Sharda University, Greater Noida, \\ Uttar Pradesh, India. Email: madhanjeyaraman@gmail.com.
}

\begin{abstract}
The large economic burden on the global health care systems is due to the increasing number of symptomatic osteoarthritis (OA) knee patients whereby accounting for greater morbidity and impaired functional quality of life. The recent developments and impulses in molecular and regenerative medicine have paved the way for inducing the biological active cells such as stem cells, bioactive materials, and growth factors towards the healing and tissue regenerative process. Mesenchymal stem cells (MSCs) act as a minimally invasive procedure that bridges the gap between pharmacological treatment and surgical treatment for OA. MSCs are the ideal cell-based therapy for treating disorders under a minimally invasive environment in conjunction with cartilage regeneration. Due to the worldwide recognized animal model for such cell-based therapies, global researchers have started using the various sources of MSCs towards cartilage regeneration. However, there is a lacuna in literature on the comparative efficacy and safety of various sources of MSCs in OA of the knee. Hence, the identification of a potential source for therapeutic use in this clinical scenario remains unclear. In this article, we compared the therapeutic effects of various sources of MSCs in terms of efficacy, safety, differentiation potential, durability, accessibility, allogenic preparation and culture expandability to decide the optimal source of MSCs for OA knee
\end{abstract}

Keywords: Osteoarthritis (OA); mesenchymal stem cells (MSCs); bone marrow; stromal vascular fraction; orthobiologics

Received: 16 October 2020; Accepted: 25 April 2021; Published: 09 July 2021.

doi: $10.21037 /$ sci-2020-055

View this article at: http://dx.doi.org/10.21037/sci-2020-055

\footnotetext{
^ ORCID: Sathish Muthu, 0000-0002-7143-4354; Madhan Jeyaraman, 0000-0002-9045-9493; Rashmi Jain, 0000-0003-4386-6755; Arun Gulati, 0000-0001-8799-2118; Naveen Jeyaraman, 0000-0002-4362-3326; Gollahalli Shivashankar Prajwal, 0000-0001-7345-2321; Prabhu Chandra Mishra, 0000-0003-1425-2009.
} 


\section{Introduction}

The large economic burden on the global health care systems is due to the increasing number of symptomatic osteoarthritis (OA) knee patients whereby accounting for greater morbidity and impaired functional quality of life (1). The hyaline cartilage provides friction-free joint movements that protect the underlying bone from excessive load and trauma by distributing the forces equally across the joint (2). Due to the limited intrinsic healing potentiality and avascular nature of cartilage, once it gets injured, it gradually degenerates and results in OA (3). The booming ideology of "Orthobiologics" has brought up the practice of procedures that are less invasive in nature by administering substances with osteoinductive and osteogenic facets; thereby offering the benefit of decreased morbidity over classic techniques (4).

The recent developments and impulses in molecular and regenerative medicine have paved the way for inducing the biological active cells such as stem cells, bioactive materials, and growth factors towards the healing and tissue regenerative process (5). In this connotation, Mesenchymal stem cells (MSCs) are the ideal cell-based resort for treating disorders under a minimally invasive environment in conjunction with tissue regeneration (6). The efficacy of such cell therapies in animal models has been widely recognized $(7,8)$.

MSCs act as a minimally invasive procedure that bridges the gap between pharmacological treatment and surgical treatment for OA. It provides a strong and positive balance between pro-apoptotic and anti-apoptotic molecules, proinflammatory and anti-inflammatory cytokines \& proangiogenic and anti-angiogenic factors for rejuvenation of degenerated cartilaginous tissues (9). MSCs upregulate tissue inhibitors of metalloproteinases such as TIMPs-1, -3 , and -4 by downregulating the signaling molecules of matrix metalloproteinases such as MMP-1, -3, -13, and -28 and upregulating ADAMTS-4 and 5 which lead to normal joint homeostasis (10).

\section{Physiology of MSC action in OA Knee}

Growth factors and BMP 2 and 7 are reported to exercise anabolic and anti-inflammatory effects and noteworthy these are present in higher concentrations in BMAC (11). There is induced production of interleukin-1 receptor antagonist (IL-1Ra) molecule in significant concentration by the MSCs and these produced molecules execute the bioactivity of inhibiting IL-1 catabolism (12). This interesting biological approach renders symptomatic relief in pain $(13,14)$. MSCs also support neoangiogenesis through VEGF-A, VEGF-D, HGF, IGF-1, PDGF, PIGF, IL-6, EPO, MCP-1 and cellular proliferation through KGF, FGF-2, VEGF, IGF, PDGF, HGF $(11,14)$. MSCs exerted enhanced chondroprotection through diminished pro-inflammatory mediator production and increased antiinflammatory cytokine production including IDO, PGE2, TGF- $\beta$, TSG-6, HGF, NO, HO-1, HLA-G. They mediate their anti-apoptotic actions through VEGF, HGF, IGF-1, TGF- $\beta$, GM-CSF (12-14). A schematic diagram elaborating on the physiological action of MSC in immunomodulation of OA pathogenesis is given in Figure 1.

\section{Sources of MSCs}

MSCs are pluripotent cells with the potential to differentiate into the chondrogenic and osteogenic lineage. They can be derived and isolated from various autologous sources such as bone marrow, adipose tissue, synovium, endometrium, peripheral blood (PB), and allogenic sources such as placenta, umbilical cord, amniotic fluid as shown in Figure 2. However, evidence to delineate the ideal source of MSCs for use in OA knee remains unclear (15). In this review, we elaborate on the various types of MSCs available for therapeutic use and their merits and demerits to address the gap in knowledge in literature.

\section{Embryonic stem cells (ESCs)}

ESCs are derived from the inner cell mass of the blastocyst. Preclinical and clinical studies have proved the significant potential for cartilage engineering. ESCs are totipotent cells (16). ESCs provide numerous numbers of undifferentiated cells which may differentiate into a cell of a particular lineage (17). The cultured ESCs provide $3 \mathrm{D}$ scaffolds for cartilage engineering (18). ESCs are pluripotent, but their use raises ethical concerns, and additionally upon transplantation, they potentially give rise to tumors $(19,20)$. Under the controlled growth conditions, ESCs maintained phenotype and genotype along with maintenance of MSC cell surface markers and exponential proliferation of cellular lineage (21). Toh et al. demonstrated neochondrogenesis and ECM production under appropriate growth factors, cytokines, and hyaluronic acid-based hydrogels (22). 


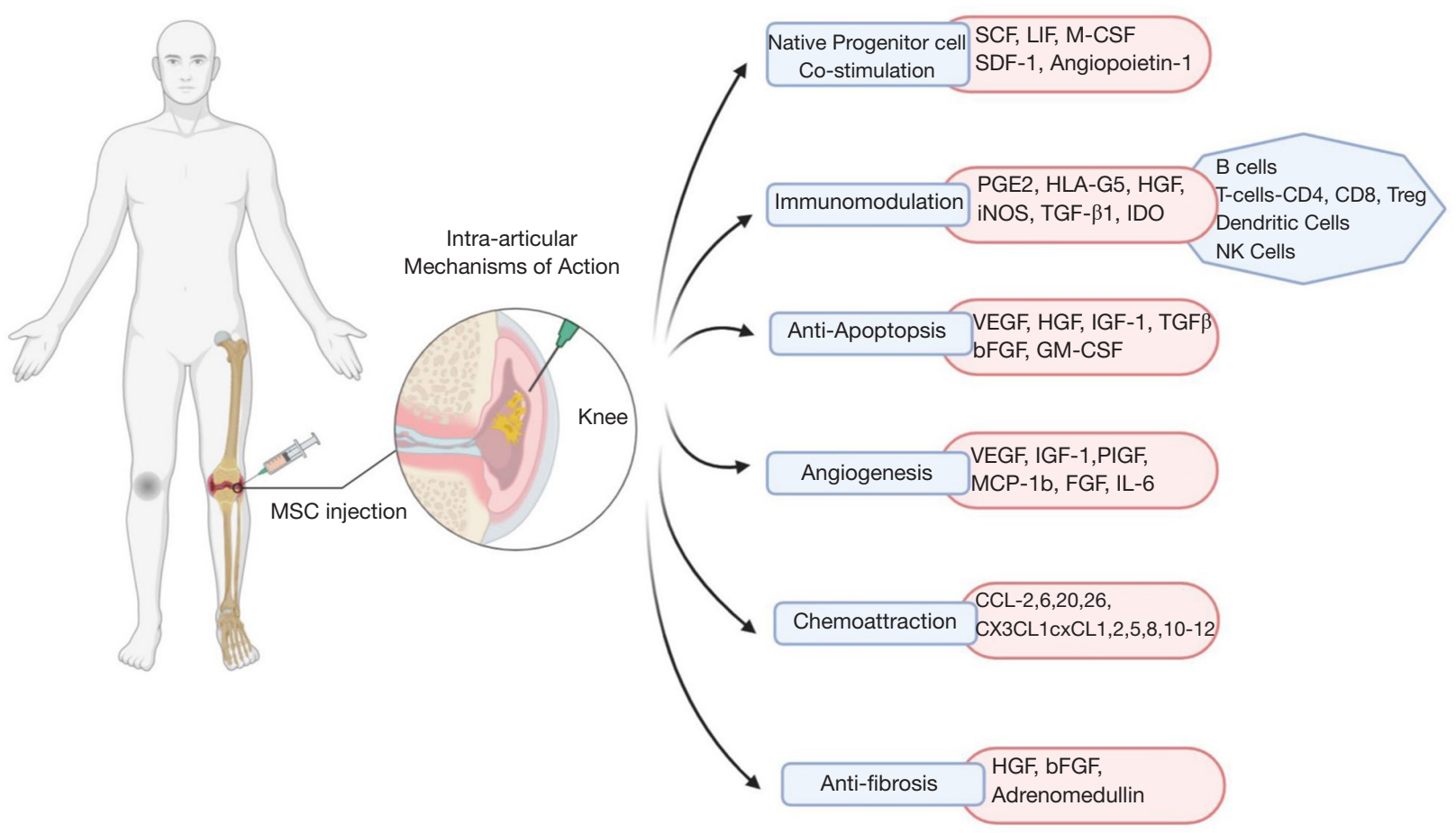

Figure 1 Schematic diagram elaborating on the physiological action of MSC in immunomodulation of OA pathogenesis. MSC, mesenchymal stem cell; OA, osteoarthritis.

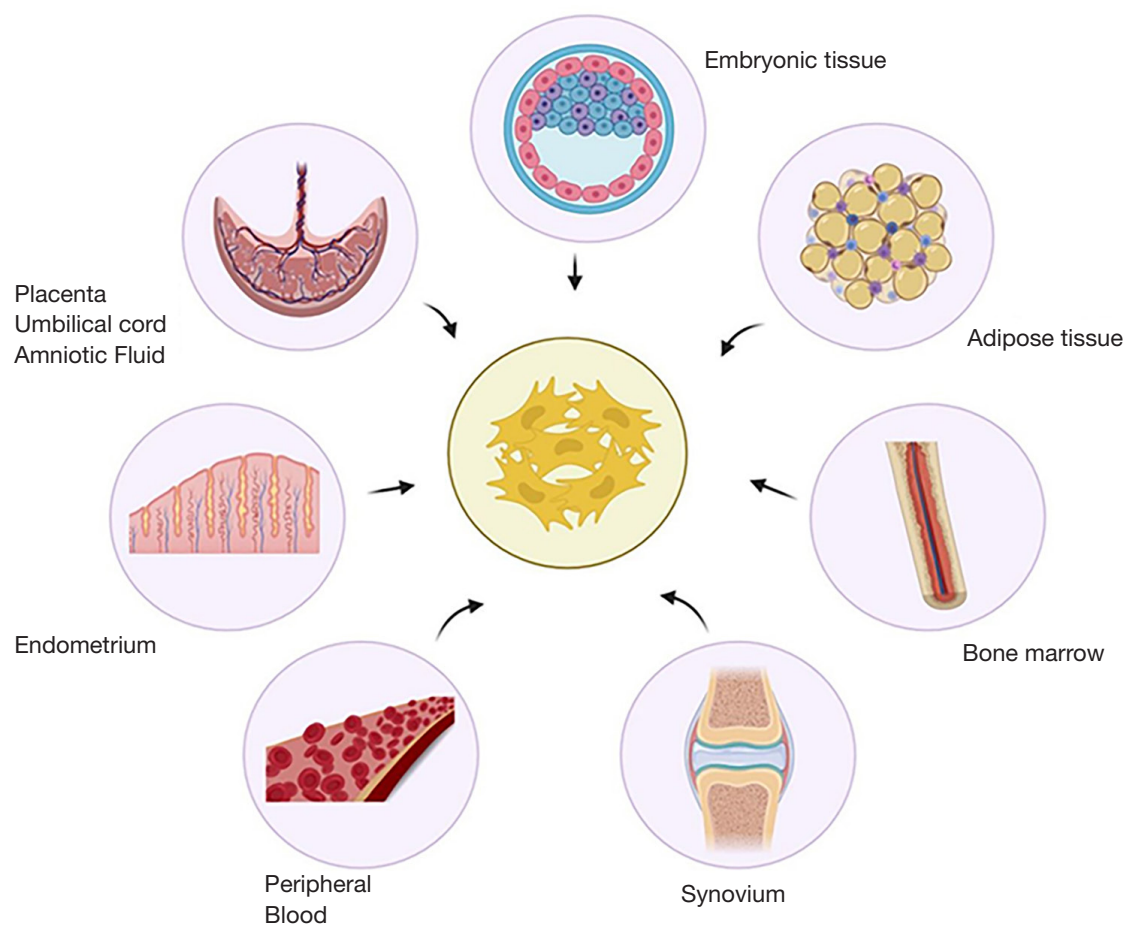

Figure 2 Sources of mesenchymal stem cells with therapeutic potential. 


\section{Bone marrow derived MSCs (BM-MSCs)}

In 1970, Alexander Friedenstein demonstrated the definitive regenerating capacity of bone marrow (23). The major source of bone marrow-derived MSCs is the iliac crest and shafts of long bones. Various researchers have reported that BMMSCs showed fibroblastoid cells with plastic adhered morphology and non-phagocytic in nature $(24,25)$. BM-MSCs showed differentiation towards osteogenic, adipogenic, and chondrogenic responses with the expression of endothelial or hematopoietic specific markers (26). BM-MSCs express CD146 in humans (27) and CXCL12, Nestin, leptin receptor, and Prx-1 in mice $(28,29)$. The osteogenic potential of BM-MSC varies as a few studies prove the greater osteogenic potential (30-32) and a few prove the equal osteogenic potential (33-35) when compared with AD-MSCs. BM-MSC exhibits an inferior chondrogenic potential when compared with AD-MSC (36) and superior response when compared with Sy-MSCs (37).

\section{Adipose tissue derived MSCs (AD-MSCs)}

In recent years, the cells with major regenerative, rejuvenative, and reconstructive potentials were attributed to adipose tissue-derived MSCs due to the possession of characteristics of mesenchymal stem/stromal cells (38). $\mathrm{AD}-\mathrm{MSCs}$ are isolated from lipoaspiration as an aqueous fraction from abdominal fat. The components of SVF are the combination of adipose-derived stromal cells, endothelial precursor cells, mature endothelial cells, lymphocytes, pericytes, pre-adipocytes, and mature adipocytes $(39,40)$. For bone and cartilage regeneration, the recent advances in the field of molecular and translational medicine have placed SVF at the highest regenerative potential horizon (41). Since they possess MSC-like properties, SVF renders a better regenerative potential, immunomodulation, antiinflammation, and neoangiogenesis at the site of action (42).

Despite the better translational potential of SVF in regenerative medicine, the challenges are viewed in the form of isolation and quantification of cellular components in SVF. Due to the presence of various cellular components in the SVF mixture, adipose-derived stem cells share a common cell surface antigen of hematopoietic stem cell CD34 as proposed by the International Society of Cellular Therapy (ISCT). Various researchers stated that SVF has a strong potential for regenerating tissues like MSCs (38).

SVF mimics the morphology of fibroblasts and possesses MSCs like properties (43). Due to the MSC-like property of SVF, it induces the differentiation of different lineage of cells like osteoblast, chondroblast, myoblast, and adipoblast $(44,45)$. The cellular mixture of SVF possesses cell surface antigens of both HSCs (CD-34 and 45) and MSCs (CD105 and 146) (46). SVF cells share common cell surface antigens of bone marrow-derived MSCs such as CD-24, 29, 31, 44, 45, 71, 90, 105/SH2, and SH3 (47). Since adipose tissue contains various components of a cellular mixture, the concept of allogenicity with adipose tissue-derived stem cells is questionable. AD-MSCs exhibit significant osteogenic potential with the cytokines secreted by the cellular mixture and hence act as a promising therapeutic agent for bone and cartilage engineering in orthopedic disorders (48). Our recent meta-analysis found $\mathrm{AD}-\mathrm{MSC}$ s to have an upper hand compared to BM-MSCs in the management of OA knee in terms of their efficacy and safety (49).

\section{Synovium derived MSCs (Sy-MSCs)}

MSCs in synovial fluid are increased along with degenerated cartilage in OA and the gene profile of these cells is more similar to the synovial MSCs indicating their role in OA (50). In humans, MSCs derived from synovial tissue may have superior chondrogenic potential (51). In a study, the transplantation of synovial MSC resulted in full defect filling of the cartilage without any adverse clinical events (52). Animal models have revealed that the joint microenvironment has endogenous populations of synovial MSCs which have chondrogenic differentiating potential and to some extent, contribute to cartilage repair (53). Mak and colleagues demonstrated that intra-articular injection of autologous or allogeneic synovial MSCs has beneficial effects when infused into a diseased joint (54). Delgado-Enciso and colleagues recently recommended an inventive approach for cartilage regeneration which is based on the intra-articular injection of bioactive cell-free formulation (BIOF2), a compound that could promote expansion and chondrogenic differentiation of endogenous populations of synovial MSCs (55). Horie and Mizuno reported that Sy-MSCs injected into rat knees accommodated themselves to the lesion, differentiated into chondrocytes directly, and promoted cartilage regeneration without traveling to distant organs $(56,57)$. Repeated injections of Sy-MSCs have shown a chondroprotective effect and promising results in rat $\mathrm{OA}$ models (58). Successful cartilage repair following direct injection of Sy-MSCs may reflect the ability of synovial MSCs to home to chondral lesions. 


\section{Endometrium derived MSCs (En-MSCs)}

En-MSCs drew attention from global researchers for their accessibility from the source and non-posting ethical issues. In a reproductive life cycle of a woman, the endometrium undergoes over 400 cycles of regeneration (59). En-MSCs pose a greater potential for chondrogenesis via TGF- $\beta$, FGF-2, -9 \& -18 and IGF-1 (60). The isolation of EnMSCs is through the collection of menstrual blood, hysterectomized specimens, or endometrial biopsy. EnMSCs possess OCT-4 (61), SSEA-4 (62), and CD49a (63) but lacks STRO1 expression $(64,65)$. En-MSCs exhibited higher colony-forming units and proangiogenic properties than BM-MSCs (63). Alcayaga-Miranda et al. exhibited that En-MSCs produce less cytokine activation and immunosuppressive molecules than BM-MSCs (63). Wolff et al. demonstrated chondrogenic differentiation potential in En-MSCs (66). Evidence proved the presence of epithelial cell nests in the endometrium which further shown stromalepithelial interaction for differentiation into cells of bone, cartilage, and adipose tissue (67). Chen and his colleagues proved the inferior potential of En-MSCs towards chondrogenic and osteogenic nature when compared with BM-MSCs and Pl-MSCs $(68,69)$.

\section{Placental derived MSCs (Pl-MSCs) \& umbilical cord derived MSCs (Um-MSCs)}

The appeal of using Umbilical cord-derived stem cells and placenta-derived stem cells is that they are the youngest stem cells available for OA treatment. They are considered "Day Zero Cells" (70). Umbilical cord blood as well as umbilical cord tissues contain cells with good proliferative capacity and chondrogenic potential. Also harvesting these cells is a painless and non-invasive procedure (71). Recently, clinical outcomes of human UCB-MSCs (hUCB-MSCs) for cartilage regeneration have been reported (72). In a trial, it was seen that a single intra-articular injection of placental MSC derived allogenically resulted in significant symptomatic improvement as well as improvement in the thickness of cartilage in knee OA (73). Khalifeh Soltani et al. reported that an allogenic placental MSC-based product appeared safe and effective for the regeneration of hyaline-like cartilage in OA of the knee after 24 weeks of follow-up, obtained favorable clinical outcome (74). At the end of 24 weeks follow-up, they observed $10 \%$ improvement in cartilage thickness in the intervention group. Wang et al. found that Warton jelly-MSCs secreted more Glycosaminoglycans than did BM-MSCs during chondrogenic differentiation (75). A study showed the repair of articular cartilage in animal models with the help of placenta-derived MSCs grown on silk fibroin material (76). Human umbilical origin stem cells are found to mitigate OA progression in large animal models too (77). In the phase I/II trial, a repeated UC-MSC dose strategy led to a favorable safety profile and improved clinical results for the treatment of long-term pain in knee OA patients (78).

\section{Amniotic fluid derived MSCs (AF-MSCs)}

The applications of amniotic fluid-derived MSCs have proven and hold a wide range of promising healing effects in sports injuries and pathologies of bone, tendon, and cartilage disorders. AF-MSCs have a higher differentiation potential for osteogenic and chondrogenic lineage than adult stem cells (79). AF-MSCs confer a low risk of tumor development without catering to the ethical concern and epigenetic memory over ESCs (80). In vitro studies suggest that the amniotic membrane proved to be a scaffold for cellular therapy in cartilage tissue repair. Preclinical studies suggested that dehydrated human amnion chorion membrane act as a disease modifier in OA knee $(81,82)$. Attenuation of cartilage degeneration has been proved with a minced amniotic membrane in a rat MMT OA model (83). Willett et al. injected a dehydrated human amniotic membrane for the management of OA knee in the rat model and found lowered cartilage attenuation with enhanced proteoglycan and collagen II content in the regenerated cartilaginous tissue (84). In the literature, only two clinical trials on amniotic fluid-derived MSCs for management of OA knee were available. Vines et al. and Farr et al. proved the safety, efficacy, and functional outcome of amniotic fluid-derived MSCs on the management of OA knee in various $\mathrm{KL}$ grades $(85,86)$.

\section{Peripheral blood derived MSCs (PB-MSCs)}

An increasing number of studies have suggested that $\mathrm{PB}$ is a potential alternative source of MSCs, which have shown similar chondrogenic differentiation potential with bone marrow-derived MSCs (BM-MSCs) in both in vitro and in vivo studies $(87,88)$. In a series of studies performed by Saw et al., a significant amount of articular cartilage regeneration, as well as profound symptomatic relief, was seen with autologous $\mathrm{PB}$ progenitor cells $(89,90)$. In a clinical trial published in the year 2017, it was cited that 
intra-articular injection of allogenically harvested $\mathrm{PB}$ stem cells combined with hG-CSF helped in alleviating pain, disability, and better cartilage regeneration in $\mathrm{OA}$ patients and avoided TKA in these patients offering a safe and exciting possibility in the treatment of OA (91). A study by Skowroński showed superior results for cartilage regeneration by PBMSC as compared to bone marrow-derived cells (92). Another study demonstrated good evidence of articular cartilage repair, an increase in cartilage thickness as well as enhanced physical function by use of repeated injections of PBSC into the damaged joint (93). A recent review article established the use of PBMSCs in cartilage repair and regeneration to be very safe and efficacious (94). In phase II clinical trial on the use of PBSCs in an arthritic knee, it was found that these cells increase the mean cartilage thickness and improve the quality of life (95).

\section{Ethical concerns}

With the rapid advances in regenerative medicine using stem cells, ethical concerns for their use on patients have also been more stringent (96). The ethical issues that all stem cell researchers face begin with the development of a meaningful question before the clinical translation of the technology in hand which might bring about an answer which is both scientific and social value (97). The risk and benefits of the therapy to society and patients must be balanced at each stage of their research (98). Sound justification is needed to upgrade the research from animal models to human subjects (99). Minimizing the risk and harm, appropriate selection and recruitment of the subjects, and making an informed decision through consent forms are the ethical considerations involved in any clinical research, and stem cell therapy is no exception $(100,101)$. With the increase in concerns for the use of animals in preclinical research, good animal models are often inadequate to equate the effects in humans. Hence, an uncertainty continues in the first human trials using stem cells even with increased safety protocols are in place (102).

Comparative characteristics of the individual sources and the level of ethical consideration with the sources and significance are elaborated in Table 1.

\section{Ongoing research \& future directives}

Several preclinical studies and clinical trials have revealed that mesenchymal cells can be used to treat OA knees because of their self-renewal property and capacity for differentiation into the functional chondrocytes to form cartilage tissues, release various cytokines \& chemokines, and provide an appropriate conducive microenvironment to promote cartilage repair (103).

Although the reliability of such treatment methodology for OA knee is being tested in human subjects by a few clinical trials, they provide us with conflicting results and thereby clouding this only ray of hope for OA knee patients (104). To date, 87 trials have been registered in the clinical trials registry, with 57 ongoing trials and 29 completed trials with their protocols given in Table 2 .

\section{Future directives}

Globally, regenerative science in orthopedics holds the future to treat certain conditions where clinicians face stagnation and challenges in the available treatment modalities for certain diseases such as the moderate stage of progressive OA, uncontrolled rheumatoid arthritis, avascular necrosis of the head of the femur, tendinopathies, delayed and non-union of fractures, etc. (105). Stem cells and regenerative medicine hold positive health outcomes in various orthopedic disorders, which have a wide range of osteogenic and osteoinductive potentiality (4-7). Various researchers have worked on the next generation of platelet-rich plasma-like allogenic platelet lysate, plateletrich fibrin, and various types of MSCs (8-11).

The scope for further research in platelet-rich plasma and MSCs in OA relies on standardization of dosage and frequency of the injection, universal protocol on preparation methods and injection techniques, quantification of growth factors injected, the role of autologous or allogenic preparation, radiological documentation on cartilage growth, preparation and standardization for allogenic formulation and conduction of randomized controlled trials to compare the efficacy and safety of various sources of MSCs and between other methods of cellular therapy in OA knees.

\section{Conclusions}

Currently, various qualitative clinical measurements used to assess the outcomes of various sources of MSCs used in OA knee does not give an objective assessment of their efficacy. The development of appropriate surrogate systems of comparative design with more sensitive quantitative methods of outcome assessment to establish a comparative 
Table 1 Comparative characteristics of the varied sources of MSC therapy for OA knee

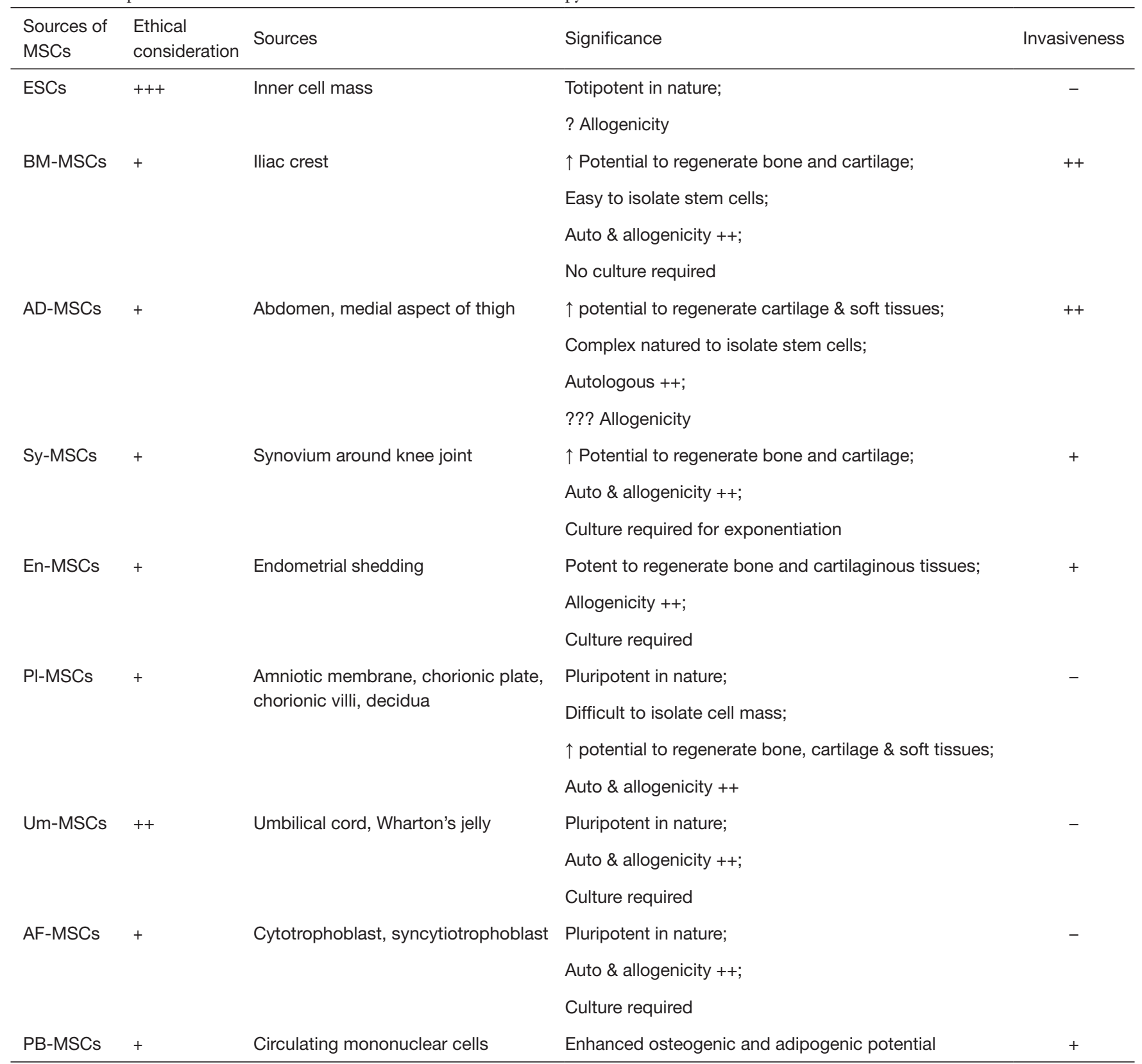

+, low; ++, medium; +++, high; -, non-invasive (allogenic); ???, doubtful; $\uparrow$, increased. ESCs, embryonic stem cells; BMMSCs, bone marrow derived MSCs; AD-MSCs, adipose tissue derived MSCs; Sy-MSCs, synovium derived MSCs; En-MSCs, endometrium derived MSCs; PI-MSCs, placental derived MSCs; Um-MSCs, umbilical derived MSCs; AF-MSCs, amniotic fluid derived MSCs; PB-MSCs, peripheral blood derived MSCs.

efficacy of various sources is the need of the hour. The available literature is limited to qualify a source to be ideal for clinical use in humans in OA knee. A consistent methodology to objectively evaluate the efficacy and safety of various sources of MSCs has to be utilized in all clinical trials to conclude their comparative effectiveness and safety.

\section{Acknowledgments}

Funding: None. 
Table 2 Completed clinical trials evaluating the role of MSC in the management of osteoarthritis knee with published results

\begin{tabular}{|c|c|c|c|c|c|c|c|c|c|}
\hline $\begin{array}{l}\text { Sl. } \\
\text { No. }\end{array}$ & Author & NCT No. & Year & Country & MSC source & Cell density & $\begin{array}{c}\text { Total } \\
\text { patients }\end{array}$ & Follow up & $\begin{array}{l}\text { Clinical } \\
\text { trial phase }\end{array}$ \\
\hline 1 & de Girolamo et al. & NCT01485198 & 2010 & Mexico & $\begin{array}{l}\text { Autologous hematopoietic } \\
\text { stem cells from bone } \\
\text { marrow }\end{array}$ & $10 \mathrm{~mL}$ BMAC & 61 & 6 months & 1 \\
\hline 2 & Taghiyar et al. & NCT00850187 & 2012 & Iran & $\begin{array}{l}\text { Autologous cultured } \\
\text { BM-MSCs }\end{array}$ & - & 6 & 12 months & I \\
\hline 4 & Shadmanfar et al. & NCT01873625 & 2013 & Iran & Autologous BM-MSCs & - & 60 & 6 months & II \& III \\
\hline 5 & Sheinkop & NCT01601951 & 2014 & USA & Autologous BMAC & - & 12 & 12 months & I \\
\hline 6 & Pers YM et al. & NCT01585857 & 2014 & France & Autologous AD-MSCs & $2 / 10 / 50 \times 10^{6} \mathrm{AD}-\mathrm{MSCs}$ & 18 & & I \\
\hline 8 & Orozco et al. & NCT01183728 & 2015 & Spain & Autologous BM-MSCs & $40 \times 10^{6} \mathrm{MSCs}$ & 12 & 24 months & $|\&| \mid$ \\
\hline 9 & Orozco et al. & NCT01586312 & 2015 & Spain & $\begin{array}{l}\text { Allogenic ex vivo cultured } \\
\text { BM-MSCs }\end{array}$ & $40 \times 10^{6} \mathrm{MSCs}$ & 30 & 12 months & $|\&| \mid$ \\
\hline 10 & Al-Najar et al. & NCT02118519 & 2016 & Jordan & $\begin{array}{l}\text { Allogenic in vitro cultured } \\
\text { BM-MSCs }\end{array}$ & $61 \times 10^{6} \pm 0.6 \times 10^{6} \mathrm{MSCs}$ & 13 & 12 months & $\|$ \\
\hline 11 & Pham et al. & NCT02142842 & 2016 & Vietnam & Autologous SVF and PRP & SVF -1.0 to $5.0 \times 10^{7}$ cells & 30 & 18 months & $|\&| \mid$ \\
\hline 12 & Ghani et al. & NCT01448434 & 2016 & Malaysia & $\begin{array}{l}\text { Ex vivo cultured adult } \\
\text { allogenic MSCs }\end{array}$ & - & 72 & 12 months & $\|$ \\
\hline 13 & Agarwal et al. & NCT01453738 & 2016 & India & $\begin{array}{l}\text { Ex vivo cultured allogenic } \\
\text { BM-MSCs }\end{array}$ & $25 / 50 / 75 / 150 \times 10^{6}$ cells & 60 & 12 months & $\|$ \\
\hline 17 & $\begin{array}{l}\text { Lamo-Espinosa } \\
\text { et al. }\end{array}$ & NCT02123368 & 2017 & Spain & $\begin{array}{l}\text { Autologous ex vivo } \\
\text { cultured BM-MSCs }\end{array}$ & $10 \times 10^{6}$ cells & 30 & 12 months & $|\&| \mid$ \\
\hline 18 & Song et al. & NCT01809769 & 2017 & China & Autologous AD-MSCs & $1 / 2 / 5 \times 10^{7}$ cells $/ 3 \mathrm{~mL}$ & 18 & 24 months & $|\&| \mid$ \\
\hline 19 & Bao and Zhang & NCT02162693 & 2017 & China & $\begin{array}{l}\text { Autologous in vitro } \\
\text { extended AD-MSCs }\end{array}$ & - & 53 & 12 months & $\|$ \\
\hline 20 & Lim et al. & NCT01041001 & 2017 & Korea & $\begin{array}{l}\text { CARTISTEM allogenic } \\
\text { UC-MSCs }\end{array}$ & $\begin{array}{l}\text { Single dose of } \\
500 \mu \mathrm{L} / \mathrm{cm}^{2} \text { containing } \\
2.5 \times 10^{6} \text { cells }\end{array}$ & 102 & 60 months & III \\
\hline 21 & Lim et al. & NCT01626677 & 2017 & Korea & $\begin{array}{l}\text { CARTISTEM allogenic } \\
\text { UC-MSCs }\end{array}$ & $\begin{array}{l}\text { Single dose of } \\
500 \mu \mathrm{L} / \mathrm{cm}^{2} \text { containing } \\
2.5 \times 10^{6} \text { cells }\end{array}$ & 103 & 48 months & III \\
\hline 22 & $\begin{array}{l}\text { Matas and } \\
\text { Espinoza }\end{array}$ & NCT02580695 & 2018 & Chile & Allogenic UC-MSCs & $\begin{array}{l}20 \times 10^{6} \text { and } 3 \mathrm{~mL} \\
\text { hyaluronic acid }\end{array}$ & 30 & 12 months & $|\&| \mid$ \\
\hline
\end{tabular}

Table 2 (continued) 
Table 2 (continued)

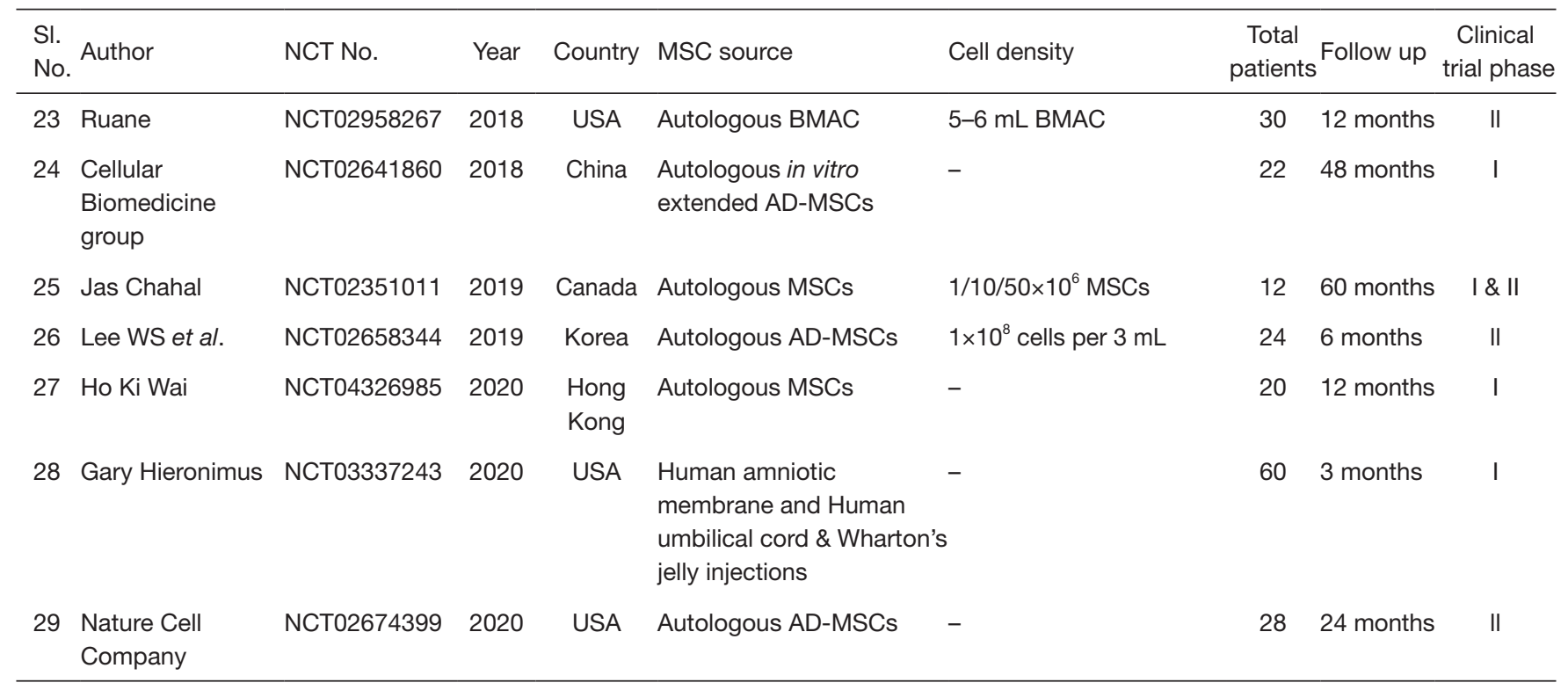

BMAC, bone marrow aspirate concentrate; BM-MSCs, bone marrow derived MSCs; AD-MSCs, adipose tissue derived MSCs; UC-MSCs, umbilical cord derived MSCs; PRP, platelet rich plasma; SVF, stromal vascular fraction.

\section{Footnote}

Conflicts of Interest: All authors have completed the ICMJE uniform disclosure form (available at http://dx.doi. org/10.21037/sci-2020-055). The authors have no conflicts of interest to declare.

Ethical Statement: The authors are accountable for all aspects of the work in ensuring that questions related to the accuracy or integrity of any part of the work are appropriately investigated and resolved.

Open Access Statement: This is an Open Access article distributed in accordance with the Creative Commons Attribution-NonCommercial-NoDerivs 4.0 International License (CC BY-NC-ND 4.0), which permits the noncommercial replication and distribution of the article with the strict proviso that no changes or edits are made and the original work is properly cited (including links to both the formal publication through the relevant DOI and the license). See: https://creativecommons.org/licenses/by-nc-nd/4.0/.

\section{References}

1. Sibille KT, Chen H, Bartley EJ, et al. Accelerated aging in adults with knee osteoarthritis pain: consideration for frequency, intensity, time, and total pain sites. Pain Rep 2017;2:e591.

2. Sophia Fox AJ, Bedi A, Rodeo SA. The basic science of articular cartilage: structure, composition, and function. Sports Health 2009;1:461-8.

3. Ramesh R, Madhan J, Kartavya C, et al. A Randomized Controlled Trial on Functional Outcome and Effectiveness of Autologous Platelet Rich Plasma Therapy Vs Corticosteroid Injection in Early Knee Osteoarthritis. Nov Tech Arthritis Bone Res 2019;3:1-9.

4. Dubey NK, Mishra VK, Dubey R, et al. Combating Osteoarthritis through Stem Cell Therapies by Rejuvenating Cartilage: A Review. Stem Cells Int 2018;2018:5421019.

5. Trams E, Kulinski K, Kozar-Kaminska K, et al. The Clinical Use of Platelet-Rich Plasma in Knee Disorders and Surgery-A Systematic Review and Meta-Analysis. Life (Basel) 2020;10:94.

6. Wang AT, Feng Y, Jia HH, et al. Application of mesenchymal stem cell therapy for the treatment of osteoarthritis of the knee: A concise review. World J Stem Cells 2019;11:222-35.

7. Lo Monaco M, Merckx G, Ratajczak J, et al. Stem Cells for Cartilage Repair: Preclinical Studies and Insights in Translational Animal Models and Outcome Measures. Stem Cells Int 2018;2018:9079538.

8. Goldberg A, Mitchell K, Soans J, et al. The use 
of mesenchymal stem cells for cartilage repair and regeneration: a systematic review. J Orthop Surg Res 2017;12:39.

9. Lopa S, Colombini A, Moretti M, et al. Injective mesenchymal stem cell-based treatments for knee osteoarthritis: from mechanisms of action to current clinical evidences. Knee Surg Sports Traumatol Arthrosc 2019;27:2003-20.

10. Spees JL, Lee RH, Gregory CA. Mechanisms of mesenchymal stem/stromal cell function. Stem Cell Res Ther 2016;7:125.

11. Weiss ARR, Dahlke MH. Immunomodulation by Mesenchymal Stem Cells (MSCs): Mechanisms of Action of Living, Apoptotic, and Dead MSCs. Front Immunol 2019;10:1191.

12. Christ B, Franquesa $M$, Najimi $M$, et al. Cellular and Molecular Mechanisms of Mesenchymal Stem Cell Actions. Stem Cells Int 2017;2017:2489041.

13. Imam MA, Mahmoud SSS, Holton J, et al. A systematic review of the concept and clinical applications of Bone Marrow Aspirate Concentrate in Orthopaedics. SICOT J 2017;3:17.

14. Kim GB, Shon OJ. Current perspectives in stem cell therapies for osteoarthritis of the knee. Yeungnam Univ J Med 2020;37:149-58.

15. Shariatzadeh M, Song J, Wilson SL. The efficacy of different sources of mesenchymal stem cells for the treatment of knee osteoarthritis. Cell Tissue Res 2019;378:399-410.

16. Thomson JA, Itskovitz-Eldor J, Shapiro SS, et al. Embryonic stem cell lines derived from human blastocysts. Science 1998;282:1145-7.

17. Levenberg S, Langer R. Advances in tissue engineering. Curr Top Dev Biol 2004;61:113-34.

18. Levenberg S, Burdick JA, Kraehenbuehl T, et al. Neurotrophin-induced differentiation of human embryonic stem cells on three-dimensional polymeric scaffolds. Tissue Eng 2005;11:506-12.

19. Roberts S, Genever P, McCaskie A, et al. Prospects of stem cell therapy in osteoarthritis. Regen Med 2011;6:351-66.

20. Toh WS, Lee EH, Cao T. Potential of human embryonic stem cells in cartilage tissue engineering and regenerative medicine. Stem Cell Rev Rep 2011;7:544-59.

21. Hwang NS, Varghese S, Zhang Z, et al. Chondrogenic differentiation of human embryonic stem cell-derived cells in arginine-glycine-aspartate-modified hydrogels. Tissue Eng 2006;12:2695-706.

22. Toh WS, Cao T. Derivation of Chondrogenic Cells from
Human Embryonic Stem Cells for Cartilage Tissue Engineering. Methods Mol Biol 2014. [Epub ahead of print]. doi: 10.1007/7651_2014_89.

23. Friedenstein AJ, Chailakhjan RK, Lalykina KS. The development of fibroblast colonies in monolayer cultures of guinea-pig bone marrow and spleen cells. Cell Tissue Kinet 1970;3:393-403.

24. Delorme B, Ringe J, Pontikoglou C, et al. Specific lineagepriming of bone marrow mesenchymal stem cells provides the molecular framework for their plasticity. Stem Cells 2009;27:1142-51.

25. Charbord P, Tavian M, Humeau L, et al. Early ontogeny of the human marrow from long bones: an immunohistochemical study of hematopoiesis and its microenvironment. Blood 1996;87:4109-19.

26. Pittenger MF, Mackay AM, Beck SC, et al. Multilineage potential of adult human mesenchymal stem cells. Science 1999;284:143-7.

27. Sacchetti B, Funari A, Michienzi S, et al. Self-renewing osteoprogenitors in bone marrow sinusoids can organize a hematopoietic microenvironment. Cell 2007;131:324-36.

28. Sugiyama T, Kohara H, Noda M, et al. Maintenance of the hematopoietic stem cell pool by CXCL12-CXCR4 chemokine signaling in bone marrow stromal cell niches. Immunity 2006;25:977-88.

29. Méndez-Ferrer S, Michurina TV, Ferraro F, et al. Mesenchymal and haematopoietic stem cells form a unique bone marrow niche. Nature 2010;466:829-34.

30. Shafiee A, Seyedjafari E, Soleimani M, et al. A comparison between osteogenic differentiation of human unrestricted somatic stem cells and mesenchymal stem cells from bone marrow and adipose tissue. Biotechnol Lett 2011;33:1257-64.

31. Wu W, Le AV, Mendez JJ, et al. Osteogenic performance of donor-matched human adipose and bone marrow mesenchymal cells under dynamic culture. Tissue Eng Part A 2015;21:1621-32.

32. Xu L, Liu Y, Sun Y, et al. Tissue source determines the differentiation potentials of mesenchymal stem cells: a comparative study of human mesenchymal stem cells from bone marrow and adipose tissue. Stem Cell Res Ther 2017;8:275.

33. De Ugarte DA, Morizono K, Elbarbary A, et al. Comparison of multi-lineage cells from human adipose tissue and bone marrow. Cells Tissues Organs 2003;174:101-9.

34. Rath SN, Nooeaid P, Arkudas A, et al. Adipose- and bone marrow-derived mesenchymal stem cells display different osteogenic differentiation patterns in 3D bioactive glass-based scaffolds. J Tissue Eng Regen Med 
2016;10:E497-E509.

35. Li X, Bai J, Ji X, et al. Comprehensive characterization of four different populations of human mesenchymal stem cells as regards their immune properties, proliferation and differentiation. Int J Mol Med 2014;34:695-704.

36. Ronzière MC, Perrier E, Mallein-Gerin F, et al. Chondrogenic potential of bone marrow- and adipose tissue-derived adult human mesenchymal stem cells. Biomed Mater Eng 2010;20:145-58.

37. Gale AL, Linardi RL, McClung G, et al. Comparison of the Chondrogenic Differentiation Potential of Equine Synovial Membrane-Derived and Bone Marrow-Derived Mesenchymal Stem Cells. Front Vet Sci 2019;6:178.

38. Bourin P, Bunnell BA, Casteilla L, et al. Stromal cells from the adipose tissue-derived stromal vascular fraction and culture expanded adipose tissue-derived stromal/stem cells: a joint statement of the International Federation for Adipose Therapeutics and Science (IFATS) and the International Society for Cellular Therapy (ISCT). Cytotherapy 2013;15:641-8.

39. Suzuki E, Fujita D, Takahashi M, et al. Adipose tissuederived stem cells as a therapeutic tool for cardiovascular disease. World J Cardiol 2015;7:454-65.

40. Bony C, Cren M, Domergue S, et al. Adipose Mesenchymal Stem Cells Isolated after Manual or Water-jet-Assisted Liposuction Display Similar Properties. Front Immunol 2016;6:655.

41. Szöke K, Brinchmann JE. Concise review: therapeutic potential of adipose tissue-derived angiogenic cells. Stem Cells Transl Med 2012;1:658-67.

42. Charles-de-Sá L, Gontijo-de-Amorim NF, Maeda Takiya $\mathrm{C}$, et al. Antiaging treatment of the facial skin by fat graft and adipose-derived stem cells. Plast Reconstr Surg 2015;135:999-1009.

43. Crisan M, Yap S, Casteilla L, et al. A perivascular origin for mesenchymal stem cells in multiple human organs. Cell Stem Cell 2008;3:301-13.

44. Caplan AI. MSCs: The Sentinel and Safe-Guards of Injury. J Cell Physiol 2016;231:1413-6.

45. Jeyaraman M, Muthu S, Ganie PA. Does the Source of Mesenchymal Stem Cell Have an Effect in the Management of Osteoarthritis of the Knee? Meta-Analysis of Randomized Controlled Trials. Cartilage 2020. [Epub ahead of print]. doi: 10.1177/1947603520951623.

46. Matsumoto D, Sato K, Gonda K, et al. Cell-assisted lipotransfer: supportive use of human adipose-derived cells for soft tissue augmentation with lipoinjection. Tissue Eng 2006;12:3375-82.
47. Zuk PA, Zhu M, Mizuno H, et al. Multilineage cells from human adipose tissue: implications for cell-based therapies. Tissue Eng 2001;7:211-28.

48. Cowan CM, Shi YY, Aalami OO, et al. Adipose-derived adult stromal cells heal critical-size mouse calvarial defects. Nat Biotechnol 2004;22:560-7.

49. Kunze KN, Burnett RA, Wright-Chisem J, et al. AdiposeDerived Mesenchymal Stem Cell Treatments and Available Formulations. Curr Rev Musculoskelet Med 2020;13:264-80.

50. Sekiya I, Ojima M, Suzuki S, et al. Human mesenchymal stem cells in synovial fluid increase in the knee with degenerated cartilage and osteoarthritis. J Orthop Res 2012;30:943-9.

51. Ogata Y, Mabuchi Y, Yoshida M, et al. Purified Human Synovium Mesenchymal Stem Cells as a Good Resource for Cartilage Regeneration. PLoS One 2015;10:e0129096.

52. Shimomura K, Yasui Y, Koizumi K, et al. First-in-Human Pilot Study of Implantation of a Scaffold-Free TissueEngineered Construct Generated From Autologous Synovial Mesenchymal Stem Cells for Repair of Knee Chondral Lesions. Am J Sports Med 2018;46:2384-93.

53. Tabera S, Pérez-Simón JA, Díez-Campelo $M$, et al. The effect of mesenchymal stem cells on the viability, proliferation and differentiation of B-lymphocytes. Haematologica 2008;93:1301-9.

54. Mak J, Jablonski CL, Leonard CA, et al. Intra-articular injection of synovial mesenchymal stem cells improves cartilage repair in a mouse injury model. Sci Rep 2016;6:23076.

55. Delgado-Enciso I, Paz-Garcia J, Valtierra-Alvarez J, et al. A phase I-II controlled randomized trial using a promising novel cell-free formulation for articular cartilage regeneration as treatment of severe osteoarthritis of the knee. Eur J Med Res 2018;23:52.

56. Horie M, Sekiya I, Muneta T, et al. Intra-articular Injected synovial stem cells differentiate into meniscal cells directly and promote meniscal regeneration without mobilization to distant organs in rat massive meniscal defect. Stem Cells 2009;27:878-87.

57. Mizuno K, Muneta T, Morito T, et al. Exogenous synovial stem cells adhere to defect of meniscus and differentiate into cartilage cells. J Med Dent Sci 2008;55:101-11.

58. Ozeki N, Muneta T, Koga H, et al. Not single but periodic injections of synovial mesenchymal stem cells maintain viable cells in knees and inhibit osteoarthritis progression in rats. Osteoarthritis Cartilage 2016;24:1061-70.

59. Tabatabaei FS, Ai J. Mesenchymal endometrial stem/ stromal cells for hard tissue engineering: a review of in vitro 
and in vivo evidence. Regen Med 2017;12:983-95.

60. Uzieliene I, Urbonaite G, Tachtamisevaite Z, et al. The Potential of Menstrual Blood-Derived Mesenchymal Stem Cells for Cartilage Repair and Regeneration: Novel Aspects. Stem Cells Int 2018;2018:5748126. doi: 10.1155/2018/5748126.

61. Faramarzi H, Mehrabani D, Fard M, et al. The Potential of Menstrual Blood-Derived Stem Cells in Differentiation to Epidermal Lineage: A Preliminary Report. World J Plast Surg 2016;5:26-31.

62. Darzi S, Zarnani AH, Jeddi-Tehrani M, et al. Osteogenic differentiation of stem cells derived from menstrual blood versus bone marrow in the presence of human platelet releasate. Tissue Eng Part A 2012;18:1720-8.

63. Alcayaga-Miranda F, Cuenca J, Luz-Crawford P, et al. Characterization of menstrual stem cells: angiogenic effect, migration and hematopoietic stem cell support in comparison with bone marrow mesenchymal stem cells. Stem Cell Res Ther 2015;6:32.

64. Kazemnejad S, Zarnani AH, Khanmohammadi M, et al. Chondrogenic differentiation of menstrual blood-derived stem cells on nanofibrous scaffolds. Methods Mol Biol 2013;1058:149-69.

65. Khanmohammadi M, Khanjani S, Bakhtyari MS, et al. Proliferation and chondrogenic differentiation potential of menstrual blood- and bone marrow-derived stem cells in two-dimensional culture. Int J Hematol 2012;95:484-93.

66. Wolff EF, Wolff AB, Hongling Du, et al. Demonstration of multipotent stem cells in the adult human endometrium by in vitro chondrogenesis. Reprod Sci 2007;14:524-33.

67. Chan RW, Gargett CE. Identification of label-retaining cells in mouse endometrium. Stem Cells 2006;24:1529-38.

68. Chen JY, Mou XZ, Du XC, et al. Comparative analysis of biological characteristics of adult mesenchymal stem cells with different tissue origins. Asian Pac J Trop Med 2015;8:739-46.

69. Gargett CE, Masuda H. Adult stem cells in the endometrium. Mol Hum Reprod 2010;16:818-34.

70. Gómez-Leduc T, Hervieu M, Legendre F, et al. Chondrogenic commitment of human umbilical cord blood-derived mesenchymal stem cells in collagen matrices for cartilage engineering. Sci Rep 2016;6:32786.

71. Park YB, Ha CW, Lee CH, et al. Cartilage Regeneration in Osteoarthritic Patients by a Composite of Allogeneic Umbilical Cord Blood-Derived Mesenchymal Stem Cells and Hyaluronate Hydrogel: Results from a Clinical Trial for Safety and Proof-of-Concept with 7 Years of Extended Follow-Up. Stem Cells Transl Med 2017;6:613-21.
72. Matas J, Orrego M, Amenabar D, et al. Umbilical CordDerived Mesenchymal Stromal Cells (MSCs) for Knee Osteoarthritis: Repeated MSC Dosing Is Superior to a Single MSC Dose and to Hyaluronic Acid in a Controlled Randomized Phase I/II Trial. Stem Cells Transl Med 2019;8:215-24.

73. Ha CW, Park YB, Chung JY, et al. Cartilage Repair Using Composites of Human Umbilical Cord Blood-Derived Mesenchymal Stem Cells and Hyaluronic Acid Hydrogel in a Minipig Model. Stem Cells Transl Med 2015;4:1044-51.

74. Khalifeh Soltani S, Forogh B, Ahmadbeigi N, et al. Safety and efficacy of allogenic placental mesenchymal stem cells for treating knee osteoarthritis: a pilot study. Cytotherapy 2019;21:54-63.

75. Wang L, Tran I, Seshareddy K, et al. A comparison of human bone marrow-derived mesenchymal stem cells and human umbilical cord-derived mesenchymal stromal cells for cartilage tissue engineering. Tissue Eng Part A 2009;15:2259-66.

76. Li F, Chen YZ, Miao ZN, et al. Human placenta-derived mesenchymal stem cells with silk fibroin biomaterial in the repair of articular cartilage defects. Cell Reprogram 2012;14:334-41.

77. Tong W, Zhang X, Zhang Q, et al. Multiple umbilical cordderived MSCs administrations attenuate rat osteoarthritis progression via preserving articular cartilage superficial layer cells and inhibiting synovitis. J Orthop Translat 2020;23:21-8.

78. MD FE. A Phase I/II, Randomized, Double-blind, Controlled Study to Assess Safety and Efficacy of Umbilical Cord-derived Mesenchymal Stromal Cells (UC-MSCs) in Patients With Knee Osteoarthritis [Internet]. clinicaltrials. gov; 2018 Dec [cited 2020 Aug 21]. Report No.: NCT02580695. Available online: https://clinicaltrials.gov/ ct2/show/NCT02580695

79. Miranda-Sayago JM, Fernández-Arcas N, Benito C, et al. Lifespan of human amniotic fluid-derived multipotent mesenchymal stromal cells. Cytotherapy 2011;13:572-81.

80. Kim K, Doi A, Wen B, et al. Epigenetic memory in induced pluripotent stem cells. Nature 2010;467:285-90.

81. Lei J, Priddy LB, Lim JJ, et al. Dehydrated human amnion/ chorion membrane (dHACM) allografts as a therapy for orthopaedic tissue repair. Tech Orthop 2017;32:149-57.

82. Jin CZ, Park SR, Choi BH, et al. Human amniotic membrane as a delivery matrix for articular cartilage repair. Tissue Eng 2007;13:693-702.

83. Raines AL, Shih MS, Chua L, et al. Efficacy of Particulate Amniotic Membrane and Umbilical Cord Tissues in Attenuating Cartilage Destruction in an Osteoarthritis 
Model. Tissue Eng Part A 2017;23:12-9.

84. Willett NJ, Thote T, Lin AS, et al. Intra-articular injection of micronized dehydrated human amnion/chorion membrane attenuates osteoarthritis development. Arthritis Res Ther 2014;16:R47.

85. Vines JB, Aliprantis AO, Gomoll AH, et al. Cryopreserved Amniotic Suspension for the Treatment of Knee Osteoarthritis. J Knee Surg 2016;29:443-50.

86. Farr J, Gomoll AH, Yanke AB, et al. A Randomized Controlled Single-Blind Study Demonstrating Superiority of Amniotic Suspension Allograft Injection Over Hyaluronic Acid and Saline Control for Modification of Knee Osteoarthritis Symptoms. J Knee Surg 2019;32:1143-54.

87. Fu WL, Ao YF, Ke XY, et al. Repair of large full-thickness cartilage defect by activating endogenous peripheral blood stem cells and autologous periosteum flap transplantation combined with patellofemoral realignment. Knee 2014;21:609-12.

88. Wang SJ, Jiang D, Zhang ZZ, et al. Chondrogenic Potential of Peripheral Blood Derived Mesenchymal Stem Cells Seeded on Demineralized Cancellous Bone Scaffolds. Sci Rep 2016;6:36400.

89. Saw KY, Anz A, Siew-Yoke Jee C, et al. Articular cartilage regeneration with autologous peripheral blood stem cells versus hyaluronic acid: a randomized controlled trial. Arthroscopy 2013;29:684-94.

90. Saw KY, Anz A, Merican S, et al. Articular cartilage regeneration with autologous peripheral blood progenitor cells and hyaluronic acid after arthroscopic subchondral drilling: a report of 5 cases with histology. Arthroscopy 2011;27:493-506.

91. Turajane T, Chaveewanakorn U, Fongsarun W, et al. Avoidance of Total Knee Arthroplasty in Early Osteoarthritis of the Knee with Intra-Articular Implantation of Autologous Activated Peripheral Blood Stem Cells versus Hyaluronic Acid: A Randomized Controlled Trial with Differential Effects of Growth Factor Addition. Stem Cells Int 2017;2017:8925132.

92. Skowroński J, Rutka M. Osteochondral lesions of the knee reconstructed with mesenchymal stem cells - results. Ortop

doi: $10.21037 /$ sci-2020-055

Cite this article as: Muthu S, Jeyaraman M, Jain R, Gulati A, Jeyaraman N, Prajwal GS, Mishra PC. Accentuating the sources of mesenchymal stem cells as cellular therapy for osteoarthritis knees—a panoramic review. Stem Cell Investig 2021;8:13.
Traumatol Rehabil 2013;15:195-204.

93. Ahmad KA, Ibrahim YA, Saber NZ, et al. MR cartilage imaging in assessment of the regenerative power of autologous peripheral blood stem cell injection in knee osteoarthritis. The Egyptian Journal of Radiology and Nuclear Medicine 2014;45:787-94.

94. Chen YR, Yan X, Yuan FZ, et al. The Use of Peripheral Blood-Derived Stem Cells for Cartilage Repair and Regeneration In Vivo: A Review. Front Pharmacol 2020;11:404.

95. Khasru MR, Salek AM, Marzen T, et al. Peripheral blood derived stem cells in OA knee at low resource setting: a phase II RCT. Osteoarthritis and Cartilage 2019;27:S512.

96. Joffe S, Miller FG. Bench to bedside: mapping the moral terrain of clinical research. Hastings Cent Rep 2008;38:30-42.

97. Emanuel EJ, Wendler D, Grady C. What makes clinical research ethical? JAMA 2000;283:2701-11.

98. Dresser R: Stem cell research as innovation: expanding the ethical and policy conversation. J Law Med Ethics 2010;38:332-41.

99. King NM, Henderson GE, Churchill LR, et al. Consent forms and the therapeutic misconception: the example of gene transfer research. IRB 2005;27:1-8.

100. Sugarman J. Human stem cell ethics: beyond the embryo. Cell Stem Cell 2008;2:529-33.

101. King NM, Perrin J. Ethical issues in stem cell research and therapy. Stem Cell Res Ther 2014;5:85.

102. Yamanaka S. Induced pluripotent stem cells: past, present, and future. Cell Stem Cell 2012;10:678-84.

103. Fang H, Huang L, Welch I, et al. Early Changes of Articular Cartilage and Subchondral Bone in The DMM Mouse Model of Osteoarthritis. Sci Rep 2018;8:2855.

104. Freitag J, Bates D, Boyd R, et al. Mesenchymal stem cell therapy in the treatment of osteoarthritis: reparative pathways, safety and efficacy - a review. BMC Musculoskelet Disord 2016;17:230.

105. Akpancar S, Tatar O, Turgut H, et al. The Current Perspectives of Stem Cell Therapy in Orthopedic Surgery. Arch Trauma Res 2016;5:e37976. 